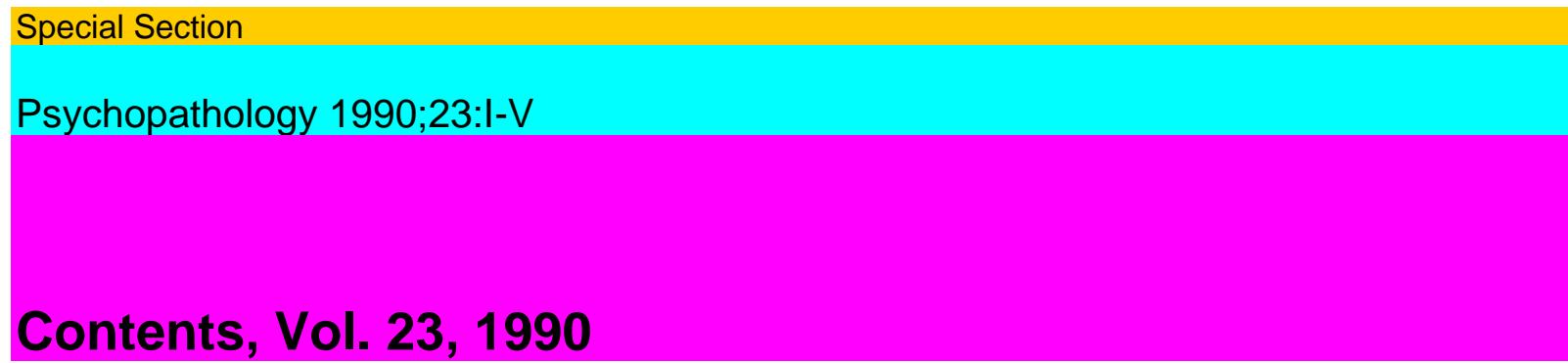

\title{
Contents Vol. 23,1990
}

No. 1 The Issue of the Core Syndrome of Endogenous Depression

Bron, B.; Lehmann, K 1

A Dimensional Approach to Severe Delusional Psychoses

Jørgensen, P.; Jensen, J 9

A Typology of Psychiatric Reactions to Motor Vehicle Accidents

Goldberg, L.; Gara, M.A 15

Discriminating Borderline from Neurotic Patients. A Study with the Holtzman Inkblot

Technique

Leisenring, F 21

A Classification System for Misidentification Syndromes

Silva, J.A.; Leong, G.B.; Shaner, A.L 27

Münchhausen Syndrome: Psychopathology and Management

Gattaz, W.F.; Dressing, H.; Hewer, W 33

The Dolittle Phenomenon: Hallucinatory Voices from Animals

Dening, T.R.; West, A 40

Latent Class Analysis of Deluded Patients

Jørgensen, P.; Jensen. J 46

Reexamination of the Relationship between Birth Order and Obsessive-Compulsive Disorder

Pollard, C.A.; Wiener, R.L.; Merkel, W.T.; Enseley, C 52

No. 2 Peter Berner - On the Occasion of his 65th Birthday

Preface

Zapotoczky, H.G.; Gabriel, E 61

Prognosis of Cardiac Phobia

Nutzinger, D.O.; Cayiroglu, S.; Grünberger, J.; Kieffer, W.; Zapotoczky, H.G 63

Obsessive-Compulsive Disorder: Course and Interaction with Depression. A Review of the

Literature

Zitterl, W.; Lenz, G.; Mairhofer, A.; Zapotoczky, H.G 73

Psychometric Assessment of DSM-III Personality Disorders: Another Facet of the Problem

Titscher, E,; Opgenoorth, E.; Ruhs, A.; Schuster, P 81

IV Contents

Diagnosis of Chronic Alcoholism - Classificatory Problems

Lesch, O.M.; Kefer, J.; Lentner, S.; Mader, R.; Marx, B.; Musalek, M.; Nimmerrichter, A.; Preinsberger, H.; Puchinger, H.; Rustembegovic, A.; Walter, H.; Zach, E 88 A Contribution to Classification of Hallucinations

Walter, H.; Podreka, I.; Steiner, M.; Suess, E.; Benda, N.; Hajji, M.; Lesch, O.M.;

Musalek, M.; Passweg, V 97

Smooth Pursuit Eye Movements in Schizophrenia: Influences of Neuroleptic Treatment and the Question of Specificity 
Küfferle, B.; Friedmann, A.; Topitz, A.; Földes, P.; Anderer, P.; Kutzer, M.; Steinberger, K. 106 The Position of Delusional Parasitosis in Psychiatric Nosology and Classification

Musalek, M.; Bach, M.; Passweg, V.; Jaeger, S 115

Are There Differences in the Course of Delusional Disorders in Different Periods of

Time?

Gabriel, E.; Schanda, H 125

No. 3 Psychopathology of Vestibular Aurae

Erkwoh, R 129

Repetitive Suicidal Crises: Characteristics of Repeating versus Nonrepeating Suicidal Visitors to

a Psychiatric Emergency ServicePeterson L.G.; Bongar, B 136

Syndrome Metamorphoses in Anorexia nervosa - An Example of Integrative Psycho-

pathologyBoning, J.; Kachel, F 146

Thought Disorder and Relapse in Schizophrenia

Wilcox, J.A 153

Predictive Value of Two Endogenicity Measures

D’haenen, H.; De Weert, D.; Feyaerts, M 157

Factors Associated with Adolescent Suicidal Attempts in Greece

Beratis, S 161

Psychiatric Assessment of Cleopatra - A Challenging Evaluation

Orland, R.M.; Orland, F.J.; Orland, P.T.M 169

Significance of the Affinity of the Epileptic to Somatesthetic Religion

Daiguji, M 176

Prolonged Fear of AIDS as an Early Symptom of Schizophrenia

Spivak, B.; Mester, R.; Babur, I.; Mark, M.; Bleich, A.; Weizman, A

No. 4-6 Leonhard Classification of Endogenous Psychoses

Preface

Beckmann, H.; Lanczik, M 191

Cycloid Psychoses

An Evaluation of the Concept of Cycloid Psychosis

Brockington, L; Roper, A 193

Cycloid Psychotic Disorder: Validation of the Concept by Means of a Follow-Up and a

Family Study

Maj, M 196

Prognostic Validity of the Cycloid Psychoses. A Prospective Follow-Up Study

Beckmann, H.; Fritze, J.; Lanczik, M205

Relationship between Cycloid Psychosis and Typical Affective Psychosis

Cutting, J 212

Puerperal and Cycloid Psychoses. Results of a Retrospective Study

Lanczik, M.; Fritze, J.; Beckmann, H 220

Epidemiology of Cycloid Psychosis

Lindvall, M; Hagnell, O.; Öhman, R 228

Cycloid Psychoses and Schizoaffective Psychoses - A Comparison of Different

DiagnosticClassification Systems and CriteriaZaudig, M 233

Leonhard and the Classiñcation of of Psychomotor Psychoses in Childhood and

AdolescenceNeumärker, K.-J 243

Cycloid Psychoses as Atypical Psychoses: 'Concordance' and 'Discordance' 
Fukuda, T 253

Nosology and Differentiated Therapy

Catamnesis of Endogenous Psychoses according to the Differential Diagnostic Method of Karl Leonhard

Trostorff, S. v.; Leonhard, K. $\dagger \quad 259$

Relations between the Classification of Endogenous Psychoses by Leonhard, the Doctrine of Pathoclisis by Vogt and the Neurological Conception of System Diseases

Schulze, H.A.F 263

Historical Aspects

The Influence of Karl Kleist on the Nosology of Karl Leonhard

Teichmann, G 267

Influence of Carl Wernicke on Karl Leonhard's Nosology

Franzek, E 277

The Importance of Karl Leonhard's Classification of Endogenous Psychoses

Perris, C 282

Switch Processes and Rapid Cycling in Bipolar Affective Disorders, Cycloid Psychoses and

Nonsystematic Schizophrenia

Bräunig, $\mathrm{P} \quad 291$

Schedule for Operationalized Diagnosis according to the Leonhard Classification of Endogenous

Psychoses

Fritze, J.; Lanczik, M 303

Development and Structure of the DCR Budapest-Nashville

Pethö, B 316

Clinical Pharmacology and Leonhard's Classification of Endogenous Psychoses

Ban, T.A 331

Studies of Course of Schizophasia

K. Kirov

K 339

Author Index 342 